\title{
Research Paper: The Effects of a 6-Week Selected Balance and Cawthorne-Cooksey Exercises on Static Balance and Mobility in Female Patients With Mul- tiple Sclerosis
}

\author{
${\text { Fatemeh Feshki' }{ }^{(D)} \text {, Abdolali Banaeifar }}^{2^{*}}$ (D) , Mehdi Kasbparast ${ }^{1}$ (D)
}

1. Department of Sport Injury and Corrective Exercise, Faculity of Physical Education, Karaj Branch, Islamic Azad University, Alborz, Iran

2. Department of Exercise Phisiology, Faculity of Physical Education, Islamic Azad University, South Branch, Tehran, Iran.

\begin{tabular}{|l|l|l|}
\hline $\begin{array}{l}\text { Use your device to scan } \\
\text { and read the artice online }\end{array}$ \\
on Static Balance and Mobility in Female Patients With Multiple Sclerosis. Physical Treatments. 2020; 10(3):169-176. http:// \\
dx.doi.org/10.32598/ptj.10.3.449.1
\end{tabular}

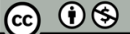

Article info:

Received: 07 Feb 2020

Accepted: 13 Jun 2020

Available Online: $01 \mathrm{Jul} 2020$

\section{A B S T RA C T}

Purpose: This quasi-experimental and applied research was conducted in 2019. The statistical population of this study included female patients with Multiple Sclerosis (MS) who were members of the Iranian MS Association.

Methods: The study subjects were selected among those with a moderate level of disability (between grades $2 \& 5$ ). From the statistical population, initially, 60 individuals were selected by a simple and accessible method; however, for some reason, some samples dropped out during the research. In total, 14, 15, and 19 individuals included the balance, CawthorneCooksey, and control groups, respectively. They were selected based on the study inclusion and exclusion criteria. The three groups were evaluated for static balance by the stork test; then, their mobility was measured by the Timed Up and Go (TUG) test at the pretest phase. Next, the two experimental groups performed the exercises for 6 weeks and 3 sessions per week. Besides, at the end of the exercise protocol, the three groups conducted the mentioned test again at the posittest step. To compare the between-groups data at the posttest, one-way Analysis of Variance (ANOVA) and Least Significant Difference (LSD) test were used to compare the differences between the research groups at a significance level 0.05 .

Results: The present research results indicated that the balance and Cawthorne-Cooksey exercises performed in the experimental groups revealed statistically significant changes in the two studied factors (both $\mathrm{P}=0.001$ ). Moreover, the LSD test results signified that in the mobility test, there was a significant difference between the control group and balance exercises group $(\mathrm{P}=0.001)$ and the control group and Cawthorne-Cooksey exercises group ( $\mathrm{P}=0.001)$. Additionally, in the static balance test, a significant difference was observed between the control group and balance exercises group $(\mathrm{P}=0.003)$ and the control group and Cawthorne-Cooksey exercises group $(\mathrm{P}=0.001)$. Finally, it was revealed that female patients with MS presented better balance and mobility after performing the exercise sessions.

Conclusion: The obtained data suggested that specialists could use the explored selected balance exercises and Cawthorne-Cooksey exercises to improve balance and mobility in patients with MS
Balance, Mobility, Cawthorne-cooksey, Multiple Sclerosis
* Corresponding Author:

Abdolali Banaeifar, PhD.

Address: Department of Exercise Phisiology, Faculity of Physical Education, Islamic Azad University, South Branch, Tehran, Iran.

Phone: +98 (912) T2251779

E-mail:alibanaeifar@yahoo.com 


\section{Highlights}

- MS is among the present century diseases with a large outbreak in Iran and worldwide

- Physicians used to advise patients with MS to avoid exercise, i.e. because of fatigue

- However, today, exercise therapy, is a cost-effective and influential method in reducing functional impairments in patients with MS.

- The problems of balance and postural control are prevalent in patients with MS.

\section{Plain Language Summary}

A large number of females and males suffer from MS. The treatment of MS consists of supportive and rehabilitation care. Physicians used to advise patients with MS to avoid exercise, however, today, exercise therapyis an influential method in reducing functional impairments in patients with MS. The problems of balance and postural control, as well as falls, are prevalent in patients with MS. Vestibular rehabilitation is among the most significant manifestations in balance disorders. The present research aimed to examine the effects of a 6-week exercises on static balance and movement ability in female patients with MS.

\section{Introduction}

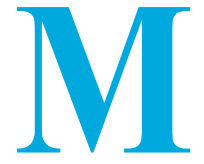

ultiple Sclerosis (MS) is among the present century diseases with a large outbreak in Iran and worldwide. It is an extremely costly disease with socioeconomic consequences. A large number of females and males suffer from this condition. The treatment of MS consists of supportive and rehabilitation care as well as the management of disease signs [1]. The disease is caused by myelin damage in the central nervous system that results in functional impairments.

Physicians used to advise patients with MS to avoid exercise, i.e. because of fatigue, temperature rising, and the aggravation of their condition [2]. However, today, exercise therapy, as a supplementary treatment, is a costeffective and influential method in reducing functional impairments in patients with MS [3]. Studies have investigated the effects of these exercises on patients with MS. Some of them have reported the positive effects of bodily activities on physical disability and life quality of this group [4]; however, some other research studies failed to demonstrate such results [5]. The problems of balance and postural control, as well as falls, are prevalent in patients with MS. These issues could reduce social relationships and the sense of control over personal life, and eventually affect the life quality of the patients [6]. Proper balance is created through interaction among the inputs of visual, sensory-physical, and vestibular systems involvement; then, appropriate motor responses are generated, i.e. transferred to eyes and spinal cord in the form of reflex commands [7]. Therefore, disruption in each part could result in balance disorders, dizziness, and other conditions, where all of these areas may be involved and impaired in patients with MS [8]. According to studies, vestibular rehabilitation is among the most significant manifestations in balance disorders [9]. Cawthorne-Cooksey exercises are part of vestibular rehabilitation which involves balance control centers, such as vestibular, visual, and deep sense systems [10]. Thus, the present research aimed to examine the effects of a 6-week selected balance and Cawthorne-Cooksey exercises on static balance and movement ability in female patients with MS.

\section{Materials and Methods}

This was a quasi-experimental study with a pretestposttest and a control group design. This research was conducted in 2019 in the form of a dissertation plan at Karaj University. The study consisted of two experimental groups (balance \& Cawthorne-Cooksey exercises) and a control group. The statistical population of the research included female patients with MS who were members of the Iranian MS Association located in Tehran City, Iran. The explored patients suffered from relapsing-remitting and secondary progressive MS. They also presented a moderate level of disability and aged $35-45$ years. The statistical sample consisted of 60 patients who were selected according to the inclusion and exclusion criteria of the study. Among the most important inclusion crite- 
ria were no medical prohibition for physical activity, a history of more than one year of the disease, no recurrence of the disease in the last three months, no history of other diseases and neurological disorders, like stroke, no defects in the vestibular system, no history of cardiovascular and respiratory diseases, the absence of musculoskeletal disorders in the spine and lower limbs, no pregnancy at the time of the research, not using aids to walk and perform daily living activities, and the ability to participate in exercise sessions. Plus, the recurrence of the disease during the research and irregular participation and having excessive absence in exercise sessions comprised the study exclusion criteria.

Furthermore, during the study, the investigated patients were treated without changes in medications; the Expanded Disability Status Scale (EDSS) score ranged between 2 and 5 in them. After identifying the research samples based on the inclusion and exclusion criteria of the study, they were randomly selected and divided into three groups of balance exercises $(n=20)$, Cawthorne-Cooksey exercises $(n=20)$, and control $(n=20)$. However, for some reason, some of the study subjects dropped out of the research process. Thus, 14, 15, and 19 individuals eventually remained in the balance exercises group, Cawthorne-Cooksey exercises group, and the control group, respectively. Then, the necessary explanations were given about the steps of researching the study participants. Accordingly, they voluntarily signed informed consent forms to participate in the research. To conduct pretest measurements, the research samples were requested to attend the desired location according to the specified schedule. After the presence of the research subjects, they first completed the basic information form; then, the anthropometric measurements of each person were performed. Next, measurements related to the performance evaluation test or the Timed Up and Go (TUG) test and static balance of individuals were performed.

In the TUG test, the time taken for a person to travel a distance of 3 meters from a normal armchair with a seat height of $45 \mathrm{~cm}$ and at her maximum safe speed, return and sit on the chair again, and lean was recorded by a stopwatch [10]. To measure static balance using the Stork test, the subject placed her hands on her thighs, while the sole of the non-leaning foot was placed in front of the inner area of the leaning foot. By maintaining this position, the study subject stayed on the chest of her leaning foot as long as possible. The effort ended whenever the heel of the leaning foot touched the floor, or the hands were detached from the thighs, or the sole of the leaning foot was detached from the knee of the leaning foot. During the test, the subject looked at the mark in front of her face at a distance of 4 meters. Each research subject should have made three attempts to record the best time as her score [11].

After completing the pretest measurements, the experimental group performed balance and Cawthorne-Cooksey exercises for 8 weeks and three sessions per week under the supervision of a researcher. Before starting the course of the exercises, a training session was held to familiarize the experimental group with the instructions of performing the exercises. The instructions of performing the exercises were as follows: the experimental groups first warmed up for 10 minutes; then, they conducted the selected exercises for 20 to 30 minutes for three weekly sessions in 8 weeks under the supervision of the researcher.

Balance Board Exercise Protocol: The study participants performed the Clark and Burden balance exercises (2005) [12] according to the progressive program presented in Table 1.

\section{Description of balance board exercises}

\section{Performance instructions (Number):}

- Standing with parallel feet, seeing the balance board, and moving the board back and forth for 30 seconds, then resting for 10 seconds;

- Standing with parallel feet, seeing the balance board and move the board to the sides for 30 seconds, then resting for 10 seconds;

- Standing on the sliding board with legs slightly apart (for about 20 seconds), moving the board from front to back for 30 seconds, then resting for 10 seconds;

- Repeating movements 1,2 , and 3 with the knees slightly bent and the hands-on the hips;

- Standing with the injured foot on the balance board and maintaining balance for 10 seconds, repeating the exercise in 6 positions with 10-second-breaks between the two repetitions.

\section{Balance Exercise Group Progressive Program}

\section{Performance instructions (Week):}

- Exercise 1 with open eyes (10 repetitions); exercise 2 with open eyes (10 repetitions); familiarity with exercise 
3 on the pad; familiarity with exercise 1 with the eyes closed; familiarity with exercise 2 with the eyes closed;

- Exercise 1 (4 repetitions with open eyes); exercise 2 (4 repetitions with open eyes); exercise 1 (4 repetitions with closed eyes); exercise 2 (4 repetitions with closed eyes); exercise 3 ( 5 repetitions with open eyes); familiarity with exercise 3 with closed eyes on the pad;

- Exercise 1 (4 repetitions with closed eyes); exercise 2 (4 repetitions with closed eyes); exercise 3 ( 5 repetitions with open eyes); exercise 3 (5 repetitions with closed eyes);

- Exercise 4 number 1 (10 repetitions with open eyes); exercise 4 number 1 (10 repetitions with closed eyes); exercise 4 number 3 ( 5 repetitions with open eyes); familiarity with exercise 4 number 1 with closed eyes; familiarity with exercise 4 number 2 with closed eyes; familiarity with exercise 4 number 3 with closed eyes;

- Exercise 4 number 1 (4 repetitions with open eyes); exercise 4 number 1 (4 repetitions with closed eyes); exercise 4 number 2 (4 repetitions with open eyes);

- Exercise 4 number 2 (4 repetitions with closed eyes); exercise 4 number 3 ( 5 repetitions with open eyes); exercise 4 number 3 ( 3 repetitions with closed eyes) Familiarity with exercise 5 on the pad;

- Exercise 4 number 1 (4 repetitions with closed eyes); exercise 4 number 1 (4 repetitions with closed eyes); exercise 4 number 3 (5 repetitions with open eyes), exercise 4 number 3 (3 repetitions with closed eyes).

\section{Cawthorne-Cooksey Exercises}

A) Eyes and head movements, sitting, first slowly, then fast:

- Looking up and down;

- Looking left and right;

- Putting fingers close to face and looking at them;

- Turning head left and right (first slowly, then fast) with open eyes;

- Moving head back and forth (first slowly, then fast) with open eyes;

- Performing movements 4 and 5 with open eyes.

\section{B) Head and torso movements, sitting:}

- Putting an object on the ground, and lifting it above the head and putting it back on the ground (during the exercise the subject should look at the object);

- Performing rotational movements in the shoulder joint;

- Bending and lifting an object in front of and behind the knees;

\section{C) Simple exercises:}

- Repeating the movements of the sections A and B, standing up;

- Sitting and getting up twice;

- Sitting and getting up twice with closed eyes;

- Turning right while getting up;

- Turning left while getting up;

- Throwing a small ball from one hand to the other (up on the horizon);

- Throwing a small ball below the knees from one hand to the other and repeating it.

Some of the Cawthorne-Cooksey (Figure 1) and balance exercises (Figure 2) are presented as per in the these figures. To assess the normality of the data, the ShapiroWilk test was used. Then, the descriptive statistics tests of mean and standard deviation were applied to describe the data. Moreover, the Paired Samples t-test was employed to compare the within-group results. Besides, one-way Analysis of Variance (ANOVA) was implemented to check the between-group for differences. The Least Significant Difference (LSD) posthoc test was used to compare the between-group data. All statistical analyses were performed at the significant level of 0.05 using SPSS.

\section{Results}

The normal distribution of the data was established by Shapiro-Wilk's test. Accordingly, parametric statistical methods were used in the analysis of research data. Oneway ANOVA was used to compare the between-group data at the posttest. A significance level of $\mathrm{P} \geq 0.05$ ) was considered for all tests (Table1). Besides, the balance exercises group $(n=20)$ had a mean \pm SD age of $75 / 37 \pm 2.52$ years, the height of $163.53 \pm 3.95 \mathrm{~cm}$, and body mass of 


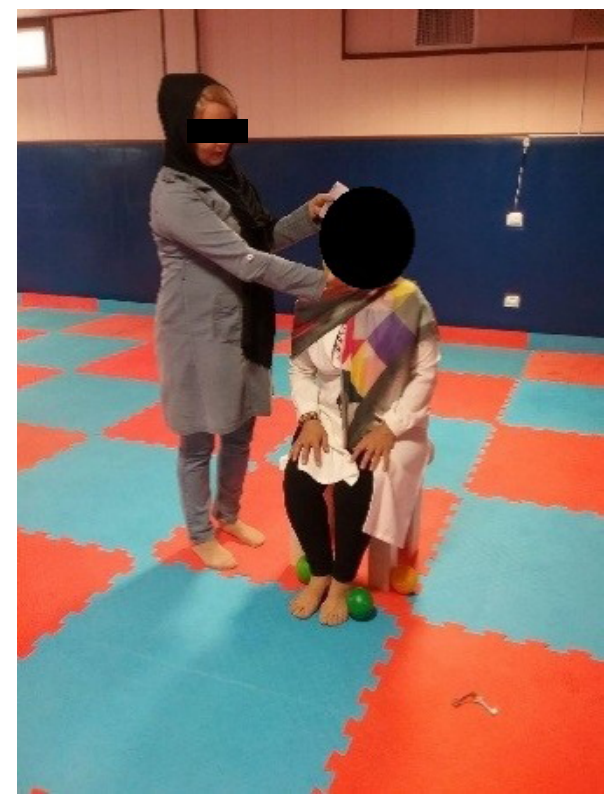

Figure 1. An example of Cawthorne-Cooksey exercises

$59.39 \pm 4.9 \mathrm{~kg}$; the Cawthorne-Cooksey exercises group $(n=20)$ had a Mean \pm SD age of $39.92 \pm .03$ years, the height of $166.86 \pm 4.214 \mathrm{~cm}$, and body mass of $61.31 \pm 5.21 \mathrm{~kg}$; the control group $(n=20)$ had a Mean \pm SD age of $42.02 \pm 3.21$ years, the height of $164.74 \pm 4.91 \mathrm{~cm}$, and body mass of $63.08 \pm 3.21 \mathrm{~kg}$.

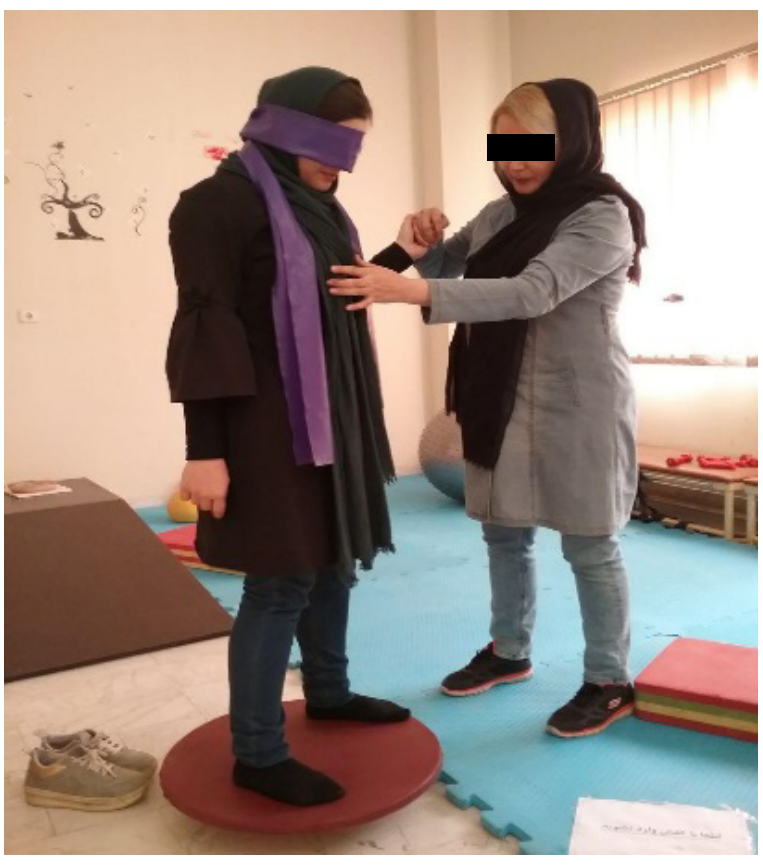

PHYSICAL TREA TMENTS

Figure 2. An example of balance exercises

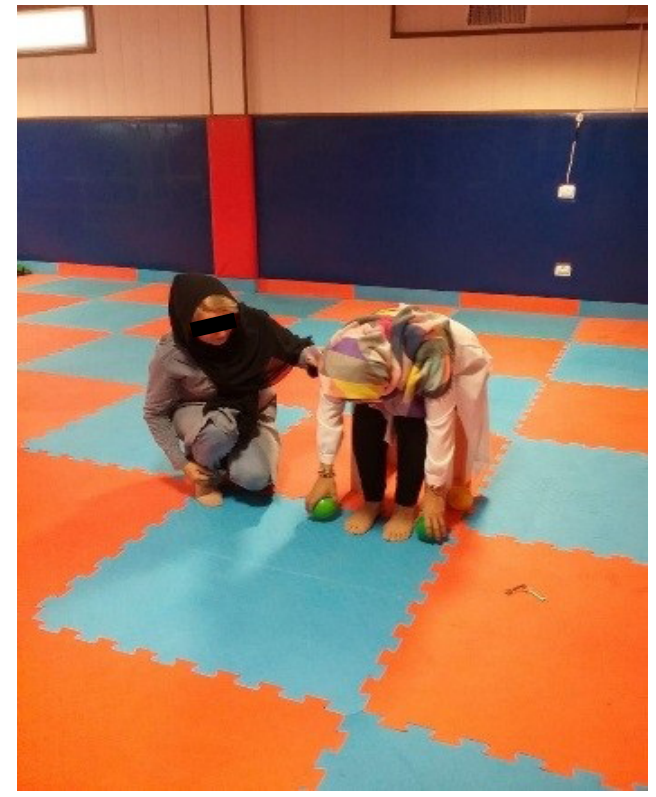

PHYSICAL TREA $\ M E N T S$

The ANCOVA results suggested that in all the mentioned variables and at the posttest phase, a significant difference existed among the three study groups $(\mathrm{P}>0.05)$. Thus, the LSD test was used to examine group differences (Table 2).

The LSD test results indicated no significant difference in motor function between balance and CawthorneCooksey exercises groups $(\mathrm{P}<0.05)$; however, there was a significant difference between balance and CawthorneCooksey exercises groups $(\mathrm{P}=0.001)$. Moreover, no significant difference was observed in mobility between balance and Cawthorne-Cooksey exercises groups $(\mathrm{P}=0.839)$. In addition, there was a significant difference between balance, control, and Cawthorne-Cooksey exercises groups in this area $(\mathrm{P}=0.001)$.

\section{Discussion}

The current research results suggested that performing Cawthorne-Cooksey exercises affected static balance and mobility in patients with MS. These results were in line with those of Zanardini et al. (2007) [13], Soltani et al. (2009) [14], Tsukamoto et al. (2015) [15]; Rebeiro et al. (2015) [16]; however, those were inconsistent with the research of Learmont and associates (2012) [4]. The reasons for such data discrepancy included the degree of physical disability among patients with MS, their age range, as well as the type of exercises used in different research studies. Balance is due to the coordination of the three systems of vision, sensory-physical, and vestibular. 
Table 1. One-way ANOVA data concerning the between-group differences in static balance variables and motor function

\begin{tabular}{|c|c|c|c|c|c|c|}
\hline Variable & State & Sum of Squares & df & Mean Squares & $\mathbf{F}$ & $\mathbf{P}$ \\
\hline \multirow{3}{*}{ Static balance } & Between groups & 648.710 & 2 & 324.355 & 8.306 & 0.001 \\
\hline & Intergroup & 1757.290 & 45 & 39.051 & & \\
\hline & Total & 2406.00 & 47 & & & \\
\hline \multirow{3}{*}{ Motor function } & Between groups & 32.253 & 2 & 16.126 & 12.259 & 0.001 \\
\hline & Intergroup & 59.197 & 45 & 1.315 & & \\
\hline & Total & 91.450 & 47 & & & \\
\hline
\end{tabular}

Table 2. LSD test results to compare differences between post-exercise research groups

\begin{tabular}{|c|c|c|c|c|}
\hline \multirow[t]{2}{*}{ Variable } & \multicolumn{2}{|c|}{ Groups } & \multirow{2}{*}{$\begin{array}{c}\text { Mean Difference } \\
0.087\end{array}$} & \multirow{2}{*}{$\begin{array}{c}\mathbf{P} \\
0.839\end{array}$} \\
\hline & Balance exercises & Cawthorne-cooksey exercises & & \\
\hline \multirow[t]{4}{*}{ Motor function } & & Balance exercise & 0.629 & 0.001 \\
\hline & Control & & & \\
\hline & & Cawthorne-cooksey exercises & 716.1 & 0.001 \\
\hline & Balance exercises & Cawthorne-cooksey exercises & 280.1 & 0.584 \\
\hline \multirow[t]{3}{*}{ Static balance } & & Static balance & 758.6 & 0003 \\
\hline & Control & & & \\
\hline & & Cawthorne-cooksey exercises & 066.8 & 0.001 \\
\hline
\end{tabular}

PHYSICAL TREA $\$ MENTS

The vestibular system with the participation of the visual and sensory-physical systems significantly impacts the multiple dimensions of balance and walking. According to the achieved results, the balance was improved in the studied patients by performing Cawthorne-Cooksey exercises; i.e. part of the vestibular exercises and involve the vestibular system. These exercises may be the reason why the static balance was improved in patients with MS. In patients with MS, balance disorders are directly affected by the transmission of neural messages involved in maintaining balance transferred to the cerebellum [16]. Changes in head and body posture due to the exercise program of Cawthorne-Cooksey may have affected the balance system; the resulting neural information transmitted to the cerebellum and commands issued from the cerebellum to various muscles in the body maintain balance [16]. Frequent eye and head movements, and head and shoulder rotations in Cawthorne-Cooksey exercises conducted by the explored patients with MS may have provided the vestibular system with the information required to orient the body in space for the brain. In other words, the vestibular nuclei are responsible for integrating messages from the vestibular organs with other messages from the visual system, cerebellum, and even the spinal cord. When incoming messages are integrated with the vestibular nuclei, they are transformed into several different areas inside the brain. These regions included the vestibular areas, thalamus, sensory-physical cortex, cerebellum, spinal cord, and oculomotor nuclei [17].

This intricate vestibular network assists individuals to spatially orientate their body concerning gravity and to recognize when to rotate the head and body. Perhaps one of the reasons that patients with MS find the right position, especially in the cases of sudden balance loss in terms of orientation, and improve their balance, is the vestibular system's function. According to the research, repeated posture control exercises in different positions may have caused the vestibular system (through its descending paths) to, directly and indirectly, influence the extensor muscle group to maintain standing position and control reflex balance when changing unexpectedly. In other words, the balance system receptors, i.e. located in the semicircular canals of the utricle and saccule of the internal ear, are stimulated by the movement of endolymph fluid. The cell body of these receptors is located in the vestibular ganglion at the end of the internal ear. For connecting to the second balance neuron, the axons reach 
the vestibular nuclei as well as the anterior horns of the gray matter of the spinal cord. Next, they connect to their motor neurons, resulting in two types of reflexes; one is the extensor reflex (it occurs in the extensor muscles of the side that may fall), and the other one is the flexor reflex (it occurs in the opposite side), resulting in balance.

Two pathways leave the vestibular nuclei through the brainstem and reach the spinal cord. These pathways are essential for postural control, especially in reactive conditions where balance is lost and needs to be restored [18]. Therefore, the Cawthorne-Cooksey exercise program might have affected this neural circuit. The vestibular system has a small sensory area called macula on the inner surface of each utricle and saccule. The maculae impact maintaining static balance, as the utricular macula is often located in a horizontal plane on the lower surface of the utricle. It also plays a critical role in determining the position of the head when it is upright. In contrast, the saccular macula often sits on a vertical plane and informs the position of the head when the person is lying down. Furthermore, the maculae work in the same way during static equilibrium to maintain balance during linear acceleration; therefore, the Cawthorne-Cooksey exercises have improved static balance in the study participants. Besides, the improvement due to the TUG test in this study could have increased muscle strength in the research subjects. This finding was in line with those of Shiri and colleagues (2017) [19].

The decrease of muscle strength in healthy individuals, and especially in patients with MS, is a health problem; it may be one of the factors affecting mobility. Numerous studies have highlighted that physical exercise, in various forms, increases muscle strength and mobility [20]. A study limitation was the problems related to the coordination with the research subjects, i.e. because of their conditions and traveling costs.

\section{Conclusion}

According to the present study data, Cawthorne-Cooksey and balance exercise significantly impacted static balance and mobility in the studied patients with MS. Thus, specialists could use such exercises for these patients. It is also recommended that researchers compare Cawthorne-Cooksey and other common exercises in patients with MS in future research.

\section{Ethical Considerations}

\section{Compliance with ethical guidelines}

All ethical principles are considered in this article. The participants were informed about the purpose of the research and its implementation stages. They were also assured about the confidentiality of their information and were free to leave the study whenever they wished, and if desired, the research results would be available to them.

\section{Funding}

This research did not receive any grant from funding agencies in the public, commercial, or non-profit sectors.

\section{Authors' contributions}

This research did not receive any specific grant from funding agencies in the public, commercial, or not-forprofit sectors.

\section{Conflict of interest}

The authors declared no conflicts of interest.

\section{References}

[1] Pazokian M, Shaban M, Zakerimoghdam M, Mehran A, Sangelagi B. [A comparison between the effect of stretching with aerobic and aerobic exercises on fatigue level in multiple sclerosis patients (Persian)]. Qom University Of Medical Sciences Journal. 2013; 7(1):50-6. http://journal.muq.ac.ir/ article-1-515-fa.html

[2] Ahmadi A, Arastoo AA, Nikbakht M, Zahednejad S, Rajabpour M. Comparison of the effect of 8 weeks aerobic and yoga training on ambulatory function, fatigue and mood status in MS patients. Iranian Red Crescent Medical Journal. 2013; 15(6):449-54. [DOI:10.5812/ircmj.3597] [PMID] [PMCID]

[3] Pilutti LA, Dlugonski D, Sandroff BM, Klaren RE, Motl RW Internet-delivered lifestyle physical activity intervention improves body composition in multiple sclerosis: preliminary evidence from a randomized controlled trial. Archives of Physical Medicine And Rehabilitation. 2014; 95(7):1283-8. [DOI:10.1016/j.apmr.2014.03.015] [PMID]

[4] Learmonth YC, Paul L, Miller L, Mattison P, Mcfadyen AK. The effects of a 12-week leisure centre-based, group exercise intervention for people moderately affected with multiple sclerosis: A randomized controlled pilot study. Clinical Rehabilitation. 2012; 26(7):579-93 [DOI:10.1177/0269215511423946] [PMID]

[5] Hogan N, Kehoe M, Larkin A, Coote S. The effect of community exercise interventions for people with $\mathrm{ms}$ who use bilateral support for gait. Multiple Sclerosis International. 2014, 2014:109142. [DOI:10.1155/2014/109142] [PMID] [PMCID] 
[6] Marandi SM, Shayegan Nejad V, Shanazari Z, Zolaktaf V. A comparison of 12 weeks of pilates and aquatic training on the dynamic balance of women with mulitple sclerosis. International Journal of Preventive Medicine. 2013; 4(Suppl 1):S110-7. [PMID] [PMCID]

[7] Farzin F, Golpayegani M, Faraji F, Shahrjerdi S, Ghasemi P. [The effect of vestibular rehabilitation on dizzines and balance in patient with multiple sclerosis (Persian)]. Journal of Arak University of Medical Sciences. 2018; 21(2):65-74. http://jams.arakmu.ac.ir/article-1-5442-fa.html

[8] Frzovic D, Morris Me, Vowels L. Clinical tests of standing balance: performance of persons with multiple sclerosis. Archives of Physical Medicine and Rehabilitation. 2000; 81(2):215-21. [DOI:10.1016/S0003-9993(00)90144-8] [PMID]

[9] Macias JD, Massingale S, Gerkin RD. Efficacy of vestibular rehabilitation therapy in reducing falls. OtolaryngologyHead and Neck Surgery. 2005; 133(3):323-5. [DOI:10.1016/j. otohns.2005.04.024] [PMID]

[10] Cattaneo D, Regola A, Meotti M. Validity of six balance disorders scales in persons with multiple sclerosis. Disability and Rehabilitation. 2006; 28(12):789-95. [DOI:10.1080/09638280500404289] [PMID]

[11] Mccurdy K, Langford G. The relationship between maximum unilateral squat strength and balance in young adult men and women. Journal of Sports Science \& Medicine. 2006; 5(2):282-8. [PMID] [PMCID]

[12] Clark VM, Burden AM. A 4-week wobble board exercise programme improved muscle onset latency and perceived stability in individuals with a functionally unstable ankle. Physical Therapy in Sport. 2005; 6(4):181-7. [DOI:10.1016/j. ptsp.2005.08.003]

[13] Zanardini FH, Zeigelboim BS, Jurkiewicz AL, Marques JM, Martins-Bassetto J. [Vestibular rehabilitation in elderly patients with dizziness (Portuguese)]. Pró-Fono Revista de Atualização Científica. 2007; 19(2):177-84. [DOI:10.1590/ S0104-56872007000200006] [PMID]

[14] Soltani M, Hejazi SM, Noorian A, Zendedel A, Ashkanifar F. [The effect of aerobic training on the improvement of expanded disability status scale (edss) in multiple sclerosis patients (Persian)]. Journal of Medical Science of Islamic Azad University of Mashhad. 2001; 5(1):15-20. https:/ / www.sid. ir/fa/journal/ViewPaper.aspx?ID=132799

[15] Tsukamoto HF, Costa VDSP, Da Silva Junior RA, Pelosi GG, De Moraes Marchiori LL, Vaz CRS, et al. Effectiveness of a vestibular rehabilitation protocol to improve the healthrelated quality of life and postural balance in patients with vertigo. International Archives of Otorhinolaryngology. 2015; 19(03):238-47. [DOI:10.1055/s-0035-1547523] [PMID] [PMCID]

[16] Abbaspourani M, Shariat Zadeh M, Lotfi G, Naghavi Alhoseini J. [The effect of balance and strength exercise training on static balance and isometric strength in girl students with mental retardation (Persian)]. Motor Behavior. 2016; 8(23):33-48. https://www.magiran.com/ paper/1548706?lang=en

[17] Ribeiro ADSB, Pereira JS. Balance improvement and reduction of likelihood of falls in older women after cawthorne and cooksey exercises. Brazilian Journal of Otorhinolaryngology. 2005; 71(1):38-46. [DOI:10.1016/S1808-8694(15)312830] [PMID]
[18] Pudjiastuti SS, Zubaidi A. Penggunaan Medial ARCHSupport dan Keseimbangan Dinamis pada Kondisi Flat Foot. Interest: Jurnal Ilmu Kesehatan. 2012; 1(1):84-8. http://jurnal. poltekkes-solo.ac.id/index.php/Int/article/view/28

[19] Shiri H, Soltanian M, Asghari N. The effect of 7 weeks of core stability and balance training on motor function and cognitive failures in women with multiple sclerosis. Motor Behavior (Research On Sport Science) 2017; 9(27):17-34. https://www.sid.ir/en/journal/ViewPaper.aspx?ID=578337

[20] Jm C, Fa C. Effects of a hydrotherapy program on flexibility and muscular strength in elderly women. Revista Brasileira de Fisioterapia. 2007; 11(4):267-72. https://www. researchgate.net/profile/Fatima_Caromano/publication/242233198_ 